MONTANA

STATE UNIVERSITY

LIBRARY

\title{
Electrical Conductivity of $\left(\mathrm{NH}_{4}\right)_{2} \mathrm{SO}_{4}$ Single Crystals
}

\section{Author: V. Hugo Schmidt}

Copyright (1969) American Institute of Physics. This article may be downloaded for personal use only. Any other use requires prior permission of the author and the American Institute of Physics. The following article appeared in Journal of Chemical Physics and may be found at http://dx.doi.org/10.1063/1.1733598.

Schmidt, V. Hugo. "Electrical Conductivity of (NH4)2SO4 Single Crystals." Journal of Chemical Physics 38, no. 11 (1963): 2783. doi: 10.1063/1.1733598.

Made available through Montana State University's ScholarWorks scholarworks.montana.edu 


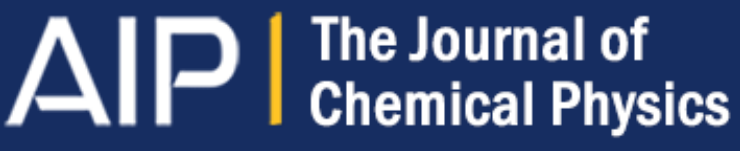

\section{Electrical Conductivity of (NH4)2SO4 Single Crystals}

V. Hugo Schmidt

Citation: The Journal of Chemical Physics 38, 2783 (1963); doi: 10.1063/1.1733598

View online: http://dx.doi.org/10.1063/1.1733598

View Table of Contents: http://scitation.aip.org/content/aip/journal/jcp/38/11?ver=pdfcov

Published by the AIP Publishing 
or by collisional energy transfer,

$$
\mathrm{C}_{2} \mathrm{H}_{4}{ }^{18} \mathrm{~F}^{*}+\mathrm{M} \rightarrow \mathrm{C}_{2} \mathrm{H}_{4}{ }^{18} \mathrm{~F}+\mathrm{M}^{*} \text {. }
$$

The stabilized fluoroethyl radical resulting from (3) will then react with iodine according to

$$
\mathrm{C}_{2} \mathrm{H}_{4}{ }^{18} \mathrm{~F}+\mathrm{I}_{2} \rightarrow \mathrm{C}_{2} \mathrm{H}_{4}{ }^{18} \mathrm{FI}+\mathrm{I} \text {. }
$$

The competitive nature of Reactions (2) and (3), followed by (4), was confirmed by a decrease in the ratio of $\mathrm{C}_{2} \mathrm{H}_{4}{ }^{18} \mathrm{FI} / \mathrm{C}_{2} \mathrm{H}_{3}{ }^{18} \mathrm{~F}$ from 4.5 to 1 on reduction of the partial pressure of $\mathrm{CF}_{4}$ from 72 to $5 \mathrm{~cm} \mathrm{Hg}$ by dilution with neon. Evidently $\mathrm{CF}_{4}$ serves as the energy sink in Reaction (3), being more effective in this respect than neon.

The efficiency of this scavenger system is shown in Fig. 1, which summarizes our results. The various yields at $1 \mathrm{~atm}$ pressure of $\mathrm{CF}_{4}$ are plotted against the pressure of $\mathrm{C}_{2} \mathrm{H}_{4}$. Scavenging of thermal fluorine atoms is essentially complete between $0.1-5$ mole $\%$ $\mathrm{C}_{2} \mathrm{H}_{4}$.

In the presence of scavenger, the large yield of $\mathrm{CF}_{3}{ }^{18} \mathrm{~F}$ is reduced to only $3.2 \%$ of the total ${ }^{18} \mathrm{~F}$ activity. Further, a yield of $1.8 \% \mathrm{CF}_{2}{ }^{18} \mathrm{FI}$ is observed. These hot products must result from hot displacement reactions such as

and

$$
{ }^{18} \mathrm{~F}^{*}+\mathrm{CF}_{4} \rightarrow \mathrm{CF}_{3}{ }^{18} \mathrm{~F}+\mathrm{F},
$$

$$
{ }^{18} \mathrm{~F}^{*}+\mathrm{CF}_{4} \rightarrow \mathrm{CF}_{2}{ }^{18} \mathrm{~F}+2 \mathrm{~F} \text { (or } \mathrm{F}_{2} \text { ). }
$$

Reaction (6) will be followed by the thermal process,

$$
\mathrm{CF}_{2}{ }^{18} \mathrm{~F}+\mathrm{I}_{2} \rightarrow \mathrm{CF}_{2}{ }^{18} \mathrm{FI}+\mathrm{I} \text {. }
$$

Reactions (5) and (6) are completely analogous to the familiar direct substitution reactions of recoil tritium atoms with methane. ${ }^{2,8}$ They differ in being less probable by about an order of magnitude. On the basis of the model developed for the hot reactions of recoil tritium, two factors would be expected to reduce the comparative efficiency of hot fluorine. Firstly, because of the greater mass of the fluorine, the collision will be slower and the vibrational motion of the central atom is more readily excited. Energy transmission throughout the system is therefore facilitated and the event is less localized. Consequently, the probability of bond rupture and substitution at the point of impact is reduced. Secondly, steric hindrance will be more marked in fluorine approach to a $\mathrm{C}-\mathrm{F}$ bond in $\mathrm{CF}_{4}$ than in hydrogen approach to a $\mathrm{C}-\mathrm{H}$ bond in $\mathrm{CH}_{4} .{ }^{9}$

This work was supported by the U.S. Atomic Energy Commission. The authors are most grateful for the cheerful cooperation of the staff of the Yale Electron Linear Accelerator.

\footnotetext{
* Contribution No. 1718 from the Sterling Chemistry Laboratory.

1 For studies of the chemical fate of recoil fluorine in condensed systems see: A. H. W. Aten, B. Koch, and I. Kommandur, J. Am. Chem. Soc. 77, 5498 (1955), and M. Anbar and P. Neta, ibid. 84, 2673 (1962). For reference to gas-phase studies on other
}

recoil halogens see E. P. Rack and A. A. Gordus, J. Chem. Phys. 36, 287 (1962).

${ }^{2}$ For a discussion of the charge state of tritium formed by nuclear recoil see M. A. El-Sayed, P. J. Estrup, and R. Wolfgang, J. Phys. Chem. 62, 1356 (1958). Similar considerations apply to high-energy ${ }^{18} \mathrm{~F}$ from the ${ }^{19} \mathrm{~F}(\gamma, n){ }^{18} \mathrm{~F}$ process.

3 The chromatographic columns used for fluorocarbon analysis were: (i) $8-\mathrm{m}$ and $30-\mathrm{cm}$ silicone SF $96,40 \%$ (w/w) on firebrick, at $25^{\circ} \mathrm{C}$. (ii) $8-\mathrm{m}$ alumina, $30-60 \mathrm{mesh}$, at $25^{\circ} \mathrm{C}$.

${ }^{4}$ R. Wolfgang and F. S. Rowland, Anal. Chem. 30, 903 (1958).

${ }^{5} \mathrm{R}$. Wolfgang and C. MacKay, Nucleonics 16, 69 (1958),

${ }^{6}$ The abstraction reaction between thermal $\mathrm{F}$ and $\mathrm{CF}_{4}$ is energetically impossible. [The strength of the $\mathrm{C}-\mathrm{F}$ bond is $106 \mathrm{kcal}$ and that of the F-F bond $36 \mathrm{kcal}$. See T. L. Cottrell, The Strengths of Chemical Bonds (Academic Press, Inc., New York, 1954), Chap. 11.] In view of the high energy of the $\mathrm{C}-\mathrm{F}$ bond, the thermal substitution reaction will almost certainly be much slower than the analogous reaction of $\mathrm{H}$ with $\mathrm{CH}_{4}$ which itself is so slow that it has never been observed thermally; see E. W. R. Steacie, Atomic and Free Radical Reactions (Reinhold Publishing Corporation, New York, 1954), Vol. I, p. 450.

${ }^{7}$ These reactions of ${ }^{18} \mathrm{~F}$ are comparable to the reactions of $\mathrm{H}$ and $\mathrm{D}$ atoms with ethylene at $25^{\circ} \mathrm{C}$; see C. A. Heller and A. S. Gordon, J. Phys. Chem. 36, 2648 (1962).

${ }^{8}$ The abstraction reaction was not studied. No direct assay of the ${ }^{18} \mathrm{FF}$ produced was made. However, the identified products account for the entire volatile yield and this in turn accounts for $95 \%$ of the tota] ${ }^{18} \mathrm{~F}$.

${ }_{9}$ D. Urch and R. Wolfgang, J. Am. Chem. Soc. 83, 2982 (1961).

\section{Electrical Conductivity of $\left(\mathrm{NH}_{4}\right)_{2} \mathrm{SO}_{4}$ Single Crystals*}

\section{Hugo Schmidt \\ Department of Physics, Valparaiso University, Valparaiso, Indiana}

(Received 4 December 1962)

$\mathbf{T}$ HE electrical conductivity of ammonium sulfate along the crystalline $b$ axis has been measured from $-72^{\circ}$ to $+200^{\circ} \mathrm{C}$. Effects of the first-order ferroelectric transition at $-49.5^{\circ} \mathrm{C}^{1}$ were observed. Ammonium sulfate was chosen because its protons are all in $\mathrm{NH}_{4}{ }^{+}$ groups, unlike other hydrogen-bonded crystals in which electrical conductivity has been studied, such as ice ${ }^{2-5}$ and certain phosphates. ${ }^{6-8}$

The crystals were grown slowly from a solution of recrystallized reagent-grade $\left(\mathrm{NH}_{4}\right)_{2} \mathrm{SO}_{4}$ in distilled water. Conducting silver paint was used for contacts. Crystals for low-temperature runs were moistureproofed with acrylic resin spray. Temperature stability was obtained by placing the test tube containing the crystal in a liquid-filled vacuum bottle.

A three-contact method was used in measuring conductivity. The dc supply was connected to one contact. On the opposite side of each crystal a grounded guard ring surrounded a contact connected to a Keithley 200B Electrometer employing a decade shunt to provide current measurement. This shunt resistance was kept much lower than the crystal resistance between the electrometer contact and guard ring. Usually $400 \mathrm{~V}$ dc was applied, across crystals 1 to $2 \mathrm{~mm}$ thick. Conductivity was independent of applied field under these conditions, and no rectification or dissociation field effect ${ }^{4}$ was observed. 
The ferroelectric transition is characterized by large conductivity fluctuations as in $\mathrm{KD}_{2} \mathrm{PO}_{4}{ }^{7}$ In agreement with results of Hoshino et al., ${ }^{1}$ the transition occurs within $1^{\circ} \mathrm{C}$ of $-49.5^{\circ} \mathrm{C}$ for both cooling and warming runs, and causes cracks to form in the crystals. These cracks are probably responsible for several conductivity anomalies which appear in Fig. 1 and Table I, such as the huge sudden increases in current at the Curie point $T_{c}$, the low value of activation energy $E_{a}$ for Crystal $C$ in Run 4 above $T_{c}$ after the crystal passed through $T_{c}$ in Run 3, and the high value of the preexponential factor $\sigma_{0}$ for Run 4 below $T_{c}$. The low values of $E_{a}$ and $\sigma_{0}$ for Crystal $D$ indicate that conduction is controlled by impurities or cracks. This crystal and Crystal $A$ grew under less controlled conditions than Crystals $B$ and $C$. The low value of $T_{c}$ for Crystal $C$ in Run 4 is associated with a faster cooling rate than was used in Run 3 or for Crystal $D$.

Immediately after Crystal $D$ was cooled through $T_{c}$ it was allowed to warm up and the conductivity decreased with time as shown in Fig. 1. This decrease following a huge increase caused by cracking is typical. A similar but much smaller decrease in conductivity occurs when an electric field is first applied to an undamaged crystal.

The values of $\sigma_{0}$ and $E_{a}$ in Table I are obtained from least-squares fits to lines of the form

$$
\sigma=\sigma_{0} \exp \left(-E_{a} / k T\right) .
$$

The conductivity of pure $\left(\mathrm{NH}_{4}\right)_{2} \mathrm{SO}_{4}$ is found to be 29 $(\Omega \mathrm{cm})^{-1} \exp (-0.76 \mathrm{eV} / k T)$, with uncertainty limits indicated by the conductivities found for Crystals $A, B$, and $C$ separately. Conductivity is not governed by $\mathrm{NH}_{4}{ }^{+}$rotation, which has an activation energy of only $0.1 \mathrm{eV} .{ }^{9}$ It is assumed that protons are the charge carriers, as in ice ${ }^{2}$ and $\mathrm{KH}_{2} \mathrm{PO}_{4},{ }^{8}$ because all these crystals contain hydrogen bonds and show similarities in magnitude, temperature dependence, and transient behavior of conductivity.

An "infinite-temperature mobility" $\mu_{0}$ can be defined by the relation $\sigma_{0}=n_{0} e \mu_{0}$. Here $e$ is proton charge and $n_{0}$ is proton concentration based on the one to

Table I. Conductivity data.

\begin{tabular}{|c|c|c|c|c|c|}
\hline \multirow[b]{2}{*}{ Crystal } & \multirow[b]{2}{*}{ Run } & \multicolumn{2}{|c|}{$T\left({ }^{\circ} \mathrm{C}\right)$ range } & \multirow{2}{*}{$\begin{array}{c}\sigma_{0} \\
(\Omega \mathrm{cm})^{-1}\end{array}$} & \multirow{2}{*}{$\begin{array}{c}E_{a} \\
(\mathrm{eV})\end{array}$} \\
\hline & & Low & High & & \\
\hline$A, B, C$ & $1-3$ & -48 & 200 & $2.9 \times 10^{1}$ & 0.76 \\
\hline$A$ & & 26 & 200 & 3.7 & 0.68 \\
\hline$B$ & & -36 & 69 & $5.8 \times 10^{2}$ & 0.84 \\
\hline$C$ & $1-3$ & -48 & 80 & 8.8 & 0.73 \\
\hline$C$ & 4 & -72 & -55 & $6.6 \times 10^{5}$ & 0.75 \\
\hline$C$ & 4 & -50 & 22 & $1.3 \times 10^{-2}$ & 0.55 \\
\hline$D$ & & -48 & 23 & $1.7 \times 10^{-3}$ & 0.48 \\
\hline
\end{tabular}

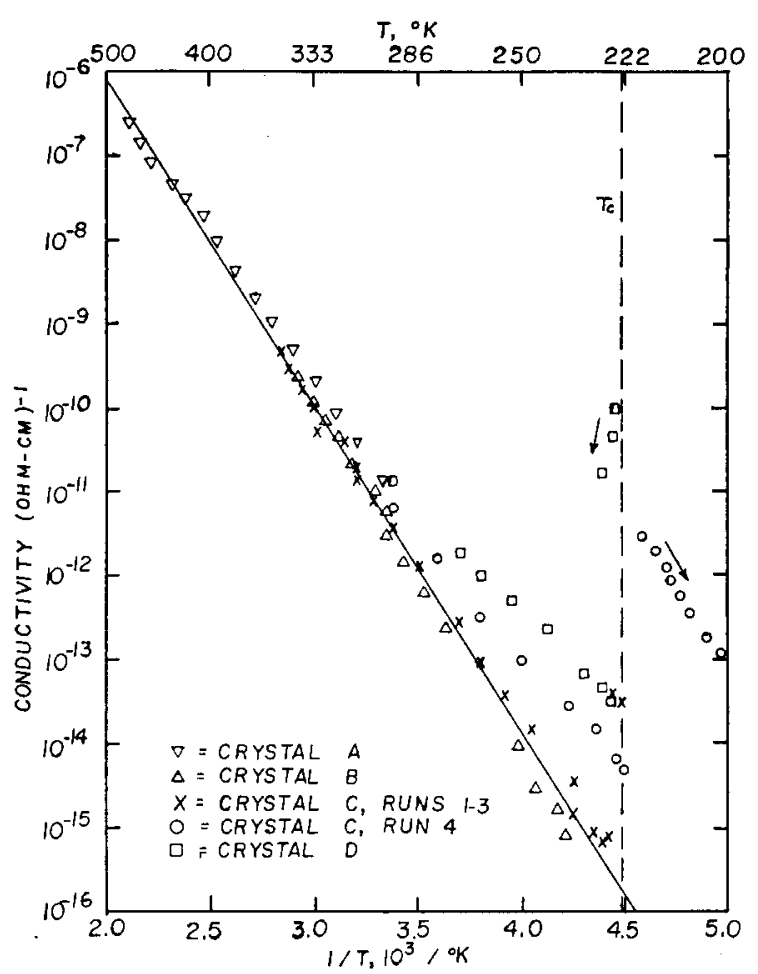

FIG. 1. Conductivity for several $\left(\mathrm{NH}_{4}\right)_{2} \mathrm{SO}_{4}$ crystals. All points near and below $T_{c}$ were obtained from cooling runs, except that the three isolated high-conductivity points for Crystal $D$ were obtained just above $T_{c}$ while warming the crystal immediately after cooling it through the transition.

eight proton sites per molecule which could be of importance in furnishing conduction protons in the temperature range studied because there are two types of $\mathrm{NH}_{4}{ }^{+}$sites and at least three nonequivalent $\mathrm{N}-\mathrm{H} \cdots \mathrm{O}$ bonds at each site. Accordingly, $\mu_{0}$ based on $\sigma_{0}=29$ $(\Omega \mathrm{cm})^{-1}$ is uncertain by a factor of 8 and lies between $2.8 \times 10^{-3}$ and $2.2 \times 10^{-2} \mathrm{~cm}^{2}(\mathrm{~V} \mathrm{sec})^{-1}$. An interesting comparison can be made with ice, for which $\mu_{0}$ based on Bradley's ${ }^{3}$ conductivity data is $2.5 \times 10^{-2} \mathrm{~cm}^{2}$ $(\mathrm{V} \mathrm{sec})^{-1}$, while the measured ${ }^{4,5}$ mobility of excess protons at $-10^{\circ} \mathrm{C}$ lies between 0.1 and $0.5 \mathrm{~cm}^{2}(\mathrm{~V} \mathrm{sec})^{-1}$.

The writer thanks Warren Gehle, Michael Goehring, Roy Knispel, Kenneth Kress, and Richard Trimble for experimental assistance, and Professor Donald L. Shirer for programming a computer to analyze the data.

* This work was supported by the National Science Foundation.

${ }^{1}$ S. Hoshino, K. Vedam, Y. Okaya, and R. Pepinsky, Phys. Rev. 112, 405 (1958).

2 J. C. Decroly, H. Gränicher, and C. Jaccard, Helv. Phys. Acta 30, 466 (1957).

${ }^{3}$ R. S. Bradley, Trans. Faraday Soc. 53, 687 (1957).

${ }_{4} \mathrm{M}$. Eigen and L. DeMaeyer, Proc. Roy. Soc. (London) A247, 505 (1958).

${ }^{5}$ L. Levi and L. Lubart, J. Chim. Phys. 58, 863 (1961).

${ }^{6}$ E. J. Murphy, Phys. Rev. 68, 283 (1945).

7 V. H. Schmidt and E. A. Uehling, Phys. Rev. 126, 447 (1962).

${ }^{8}$ V. H. Schmidt, Bull. Am. Phys. Soc. 7, 440 (1962).

${ }^{9}$ S. R. Miller, R. Blinc, M. Brenman, and J. S. Waugh, Phys. Rev. 126, 528 (1962). 